\title{
THE INFLUENCE OF THE FiniSHING STRATEGY ON THE QUALITY OF THE SURFACE
}

\author{
Lubos Kroft \\ ${ }^{a}$ Faculty of Mechanical Engineering, University of West Bohemia, Pilsen, Czech Republic
}
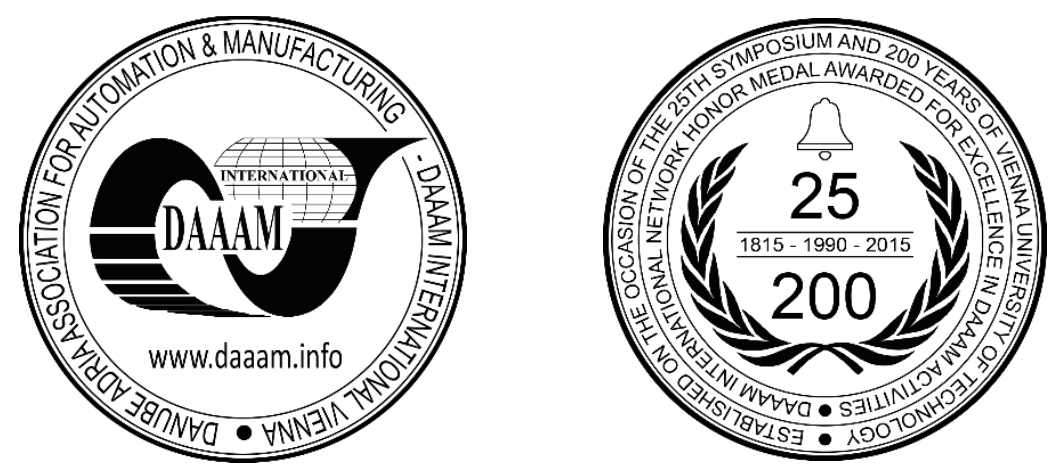

This Publication has to be referred as: Kroft, L[ubos] (2016). The Influence of the Finishing Strategy on the Quality of the Surface, Proceedings of the 27th DAAAM International Symposium, pp.0524-0533, B. Katalinic (Ed.), Published by DAAAM International, ISBN 978-3-902734-08-2, ISSN 1726-9679, Vienna, Austria

DOI: $10.2507 / 27$ th.daaam.proceedings.078

\begin{abstract}
This article explores the effects of cutting forces in a finishing strategy on the quality, and geometric and dimensional accuracy of the finished surface. It describes another part of the running research into the effectiveness of finishing strategies for sculptured surfaces. The finishing stage is very important to the effectiveness of the entire machining process. This applies to both qualitative and economic aspects. In order to select the appropriate strategy, the process engineer needs to know its impact on the quality of the resulting finished surface. It is, however, nearly impossible to monitor the changes in all parameters of the process. Fortunately, each of these changes is reflected in the magnitude and profile of the cutting force. Therefore, it is desirable to describe how the machining strategy affects the finished surface quality and the cutting force profile. Describing such dependence is the ambition of future research which will draw on the theoretical findings of the present study.
\end{abstract}

Keywords: Quality of surface; finishing; strategy; cutting forces; tool wear.

\section{Introduction}

In today's engineering production, there is a strong pressure on productivity and economy. Strict requirements make every aspect of the entire process very important. The goal is to manufacture parts to sufficient quality at reasonable costs. In the process, the resulting utility properties are dictated by finishing operations.

Finishing is therefore of major importance in the production of any part. Owing to the complexity of shaped surfaces, the development of control programs for production machines takes place exclusively in CAM software. CAM systems must therefore include advanced machining strategies for finishing, such as HSC, HFC, and others. 

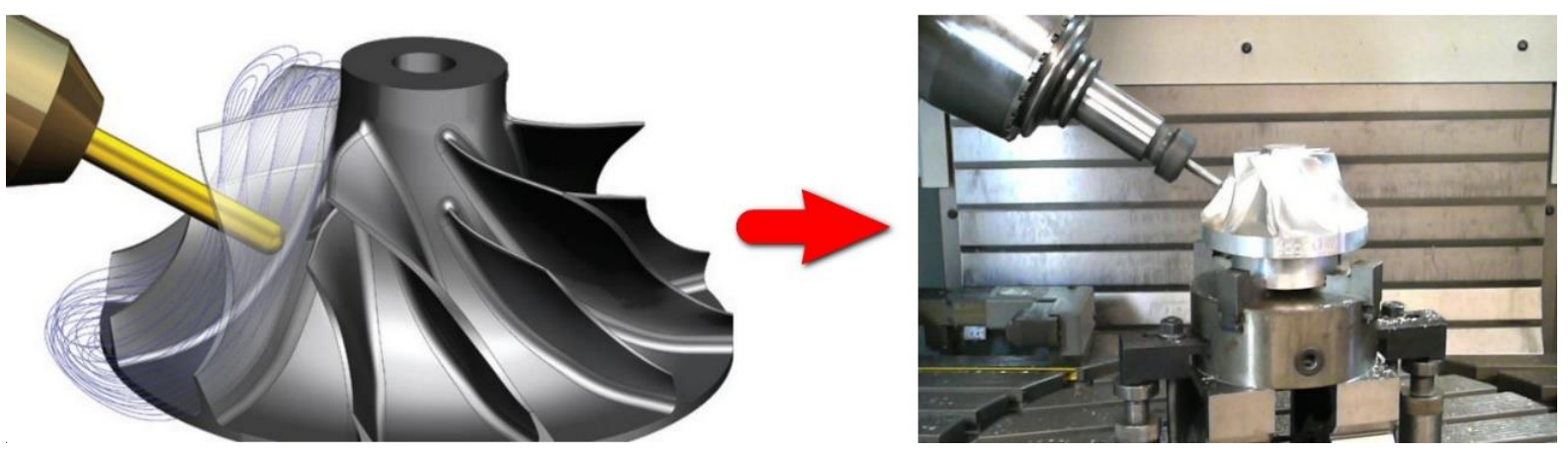

Fig. 0. Simulation of machining in CAM software and the actual process [9], [10]

Several scientific studies dealt with improving the effectiveness of finishing strategies. One of them was [14]. It compared productivity in finishing strategies in 5-axis operations. However, it did not mention any relationship between strategy and the resulting quality of the finished surface. Article [15] deals with the machined surface accuracy but only in terms of interpolation of the surface and not as a result of a particular strategy.

Nevertheless, there are studies which are closer to the issue of our interest. Moodleah and Makhanov [16] worked on improving the efficiency of tool paths through vector field-based tool path generation. Within this vector field, the directions are sought for which paths with maximum feed rate can be generated. Unfortunately, in this study only the efficiency of tool paths was sought, rather than the relation to finishing and to the resulting surface quality.

A completely different method of improving the efficiency, predominantly for finishing processes, has been presented by Imania, Sadeghib and Elbestawi [17], and Takata, Tsai, Inui and Sata. They attempted to predict cutting forces and compare the calculations with measured data. Their studies could lay foundation for future development of finishing operations.

All above-mentioned publications deal with the issue of our interest but none of them links the machining strategy and the cutting forces to the quality and dimensional and geometric accuracy of the finished surface. The objective of the present effort is to provide a theoretical basis for further research into the effectiveness of finishing sculptured surfaces.

table example:

\begin{tabular}{|ll|}
\hline $\mathrm{NC}$ & Numerical Control \\
$\mathrm{CNC}$ & Computer Numerical Control \\
$\mathrm{CAD}$ & Computer Aided Design \\
$\mathrm{X}, \mathrm{Y}, \mathrm{Z}$ & Axes in the cartesian coordinate system \\
$\mathrm{SW}$ & Software \\
$\mathrm{Fx}$ & Components of cutting force parallel to the $\mathrm{X}$ axis $[\mathrm{N}]$ \\
$\mathrm{Fy}$ & Components of cutting force parallel to the $\mathrm{Y}$ axis $[\mathrm{N}]$ \\
$\mathrm{Fz}$ & Components of cutting force parallel to the $\mathrm{Z}$ axis $[\mathrm{N}]$ \\
$\mathrm{F}$ & Total cutting force [N] \\
$\sum_{i=1}^{n} X_{i}$ & Sum of $\mathrm{X}$ elements in the interval between $\mathrm{X}_{1}$ and $\mathrm{X}_{\mathrm{n}}$ \\
$\mathrm{R}_{\mathrm{a}}$ & Arithmetic mean deviation of the profile $[\mu \mathrm{m}]$ \\
$\mathrm{R}_{\mathrm{z}}$ & Maximum height of the profile $[\mu \mathrm{m}]$ \\
$\mathrm{f}_{\mathrm{z}}$ & Feed per tooth [mm] \\
$\mathrm{r}_{\mathrm{n}}$ & Tool nose radius [mm] \\
$\mathrm{Z}$ & Number of teeth of the tool \\
$\mathrm{Z}$ & Deviation of the profile $[\mu \mathrm{m}]$ \\
\hline
\end{tabular}

Table 1. List of abbreviations

\section{Quality of machined surface}

Finishing operations are carried out to impart the required quality to a surface. Effective finishing therefore means achieving uniform quality and geometric accuracy of the machined surface. 


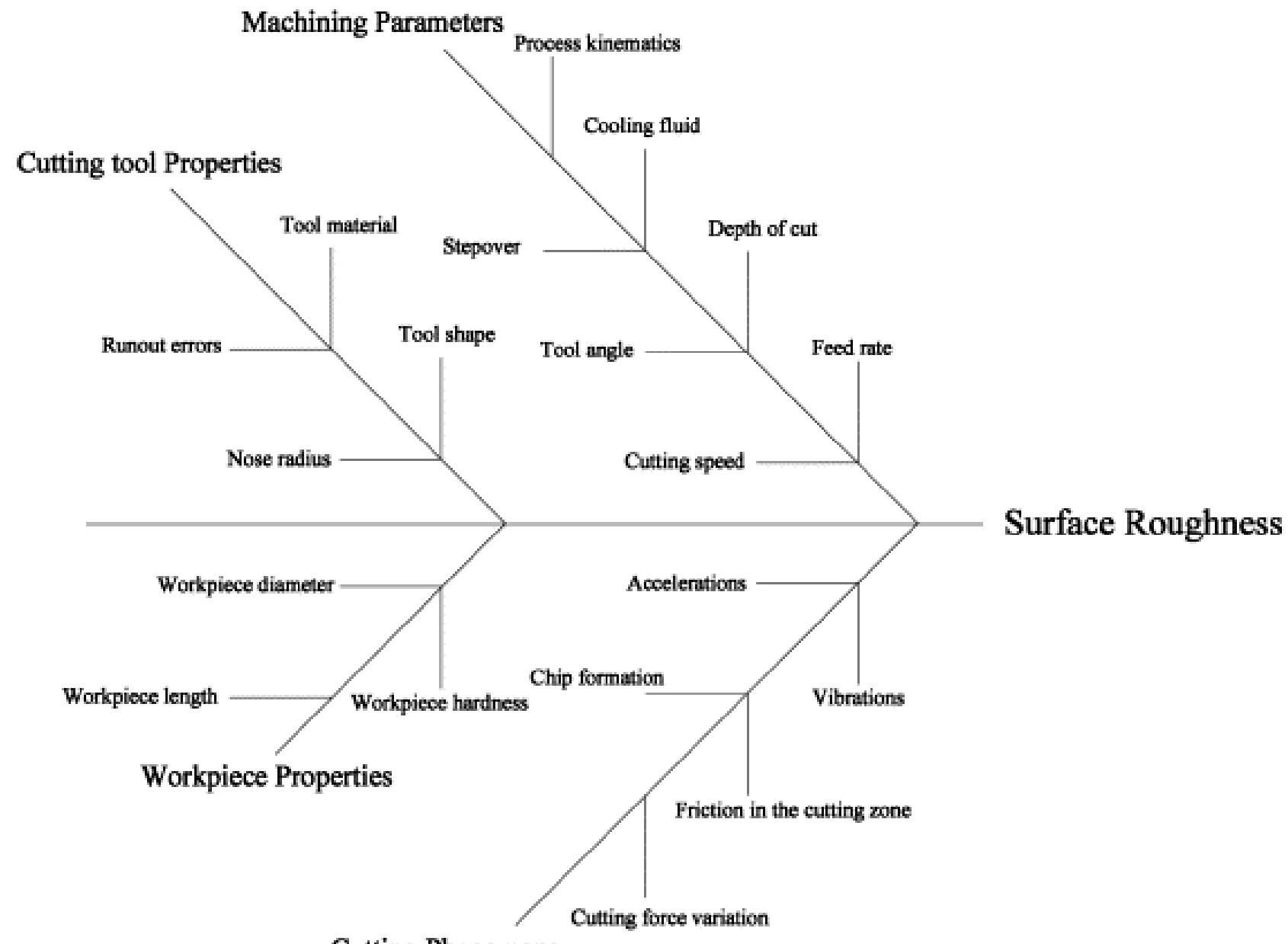

\section{Cutting Phenomena}

Fig. 0. Parameters that affect surface quality [4]

It follows from what has been said above that the magnitude of and fluctuations in the cutting force, and the proportions of its components have a major impact on the resulting quality of the finished surface. Yet, not every change in the cutting force must reflect substantially in the surface quality. All factors which can play a role in the surface quality are listed in Fig. 2. Whenever a cutting parameter changes, e.g. the cutting speed, stepover, tool diameter or others, the effect can be traced through a change in the cutting force.

The directions of components of the cutting force on a ball-end tool. More details are given in Fig. 3 and 4. The first one illustrates the effect of the inclination of the surface and the stepover on the radial component of the cutting force. [8]

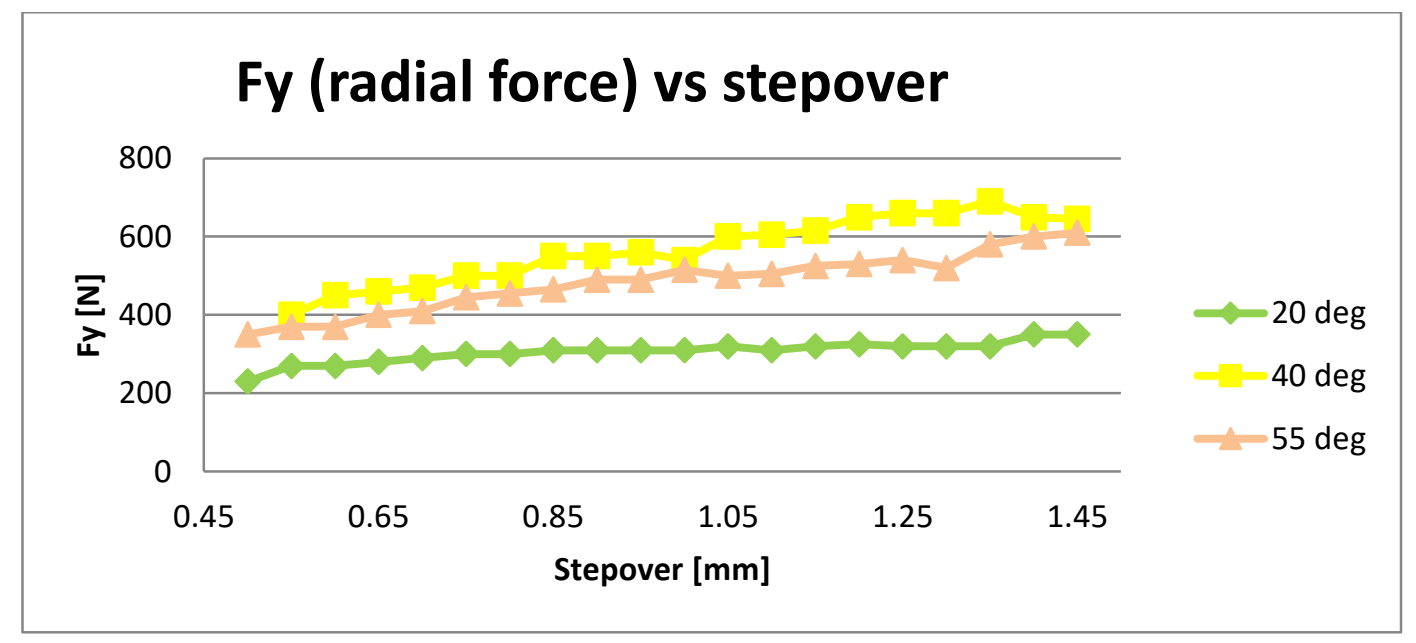

Fig. 3. Radial component of cutting force on the stepover size [9] 
The second graph shows the dependence of cutting force on the cutting speed. Although the scatter is substantial, the trend indicated by the polynomial fit is in agreement with the assumption.

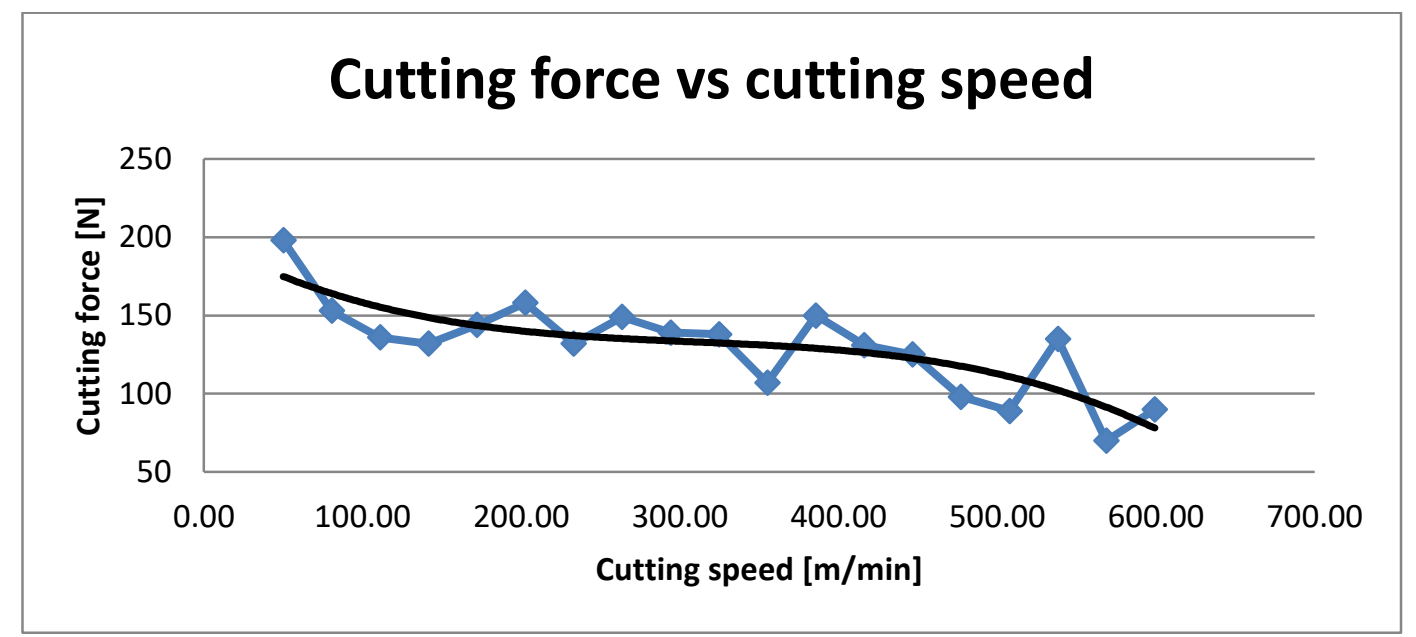

Fig. 4. Plot of cutting force vs cutting speed [9]

It is desirable to use these results to identify the relationship between cutting force variation and the quality of the finished surface. Then, the resulting quality of surface could be predicted on the basis of changes in the cutting force. In order to define such relationship, the cutting force profile must be examined in greater detail. In the following, cutting force will be studied as an indication of the potential quality and dimensional accuracy of the finished surface.

\subsection{Effect of cutting force profile on machined surface quality}

When dealing with the cutting force, it is important to consider both overall profile, variation, and maximum levels within intervals of up to tens of seconds, as well as the micro-scale variation within several tenths of a second. The quality of the finished surface depends in some way on both these scales.

The fundamental one is the macro-scale, where an entire pass or even multiple passes are considered. In the example in Fig. 5, the force magnitude in the first five seconds into the process is relatively small but it increases with time. The exact values shown in this graph are not essential for gaining understanding of the process Nevertheless, one can assume that the surface quality at the beginning will be different than at the end of the process. Between 5th and 10th second, there is fluctuation of the cutting force which could also affect the machined surface quality.

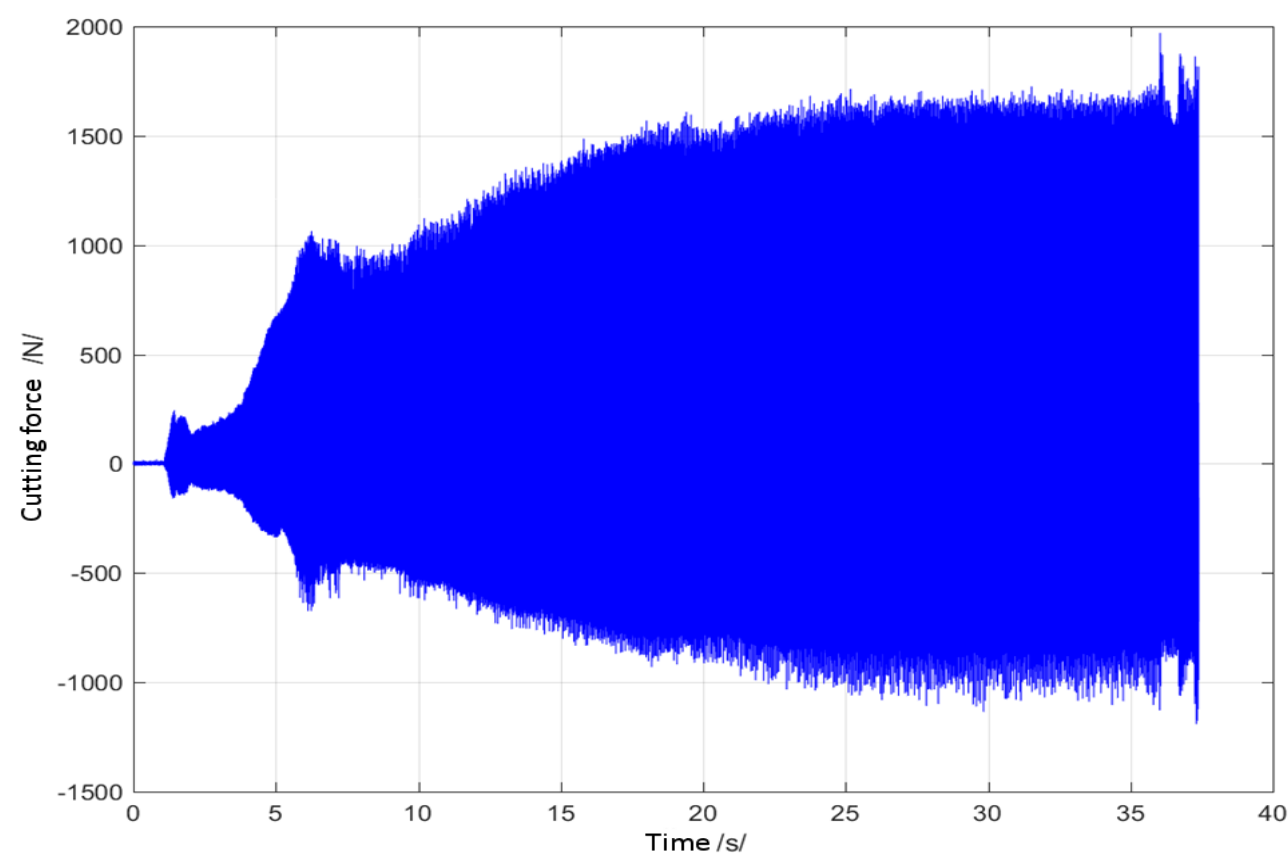

Fig. 5. Cutting force profile - macro-scale 
Gradual increase in the force and its variation can arise from varying inclination of the workpiece surface, variation in the feed rate, the stock allowance, as well as from the cutting edge becoming dull or other factors, such as inhomogeneities in the material, and others. The important conclusion is that such variations can impact on the quality of the finished surface. It is therefore desirable to develop a strategy which keeps the cutting force constant, and therefore leads to quality surface even in a sculptured workpiece.

As said above, the cutting force profile can be examined on various scales. One of them is the micro-scale represented by a force plot within an interval of several tenths of a second. Such a plot is shown in Fig. 6. It covers 0.35 seconds of the machining process which means that it includes several revolutions of the tool. The curve indicates shock loads which are typical of the milling process. The force varies from $-600 \mathrm{~N}$ to approximately $1200 \mathrm{~N}$, causing relatively severe shocks which may affect the quality of the machined surface. These shocks are due to individual teeth engaging the workpiece or more precisely entering and leaving the cut area. This variation as such is unavoidable but its magnitude can be reduced. The shocks become less severe when more teeth are engaged at the same time. In addition, it is possible to adjust the geometry or microgeometry of the cutting edge, and other parameters.

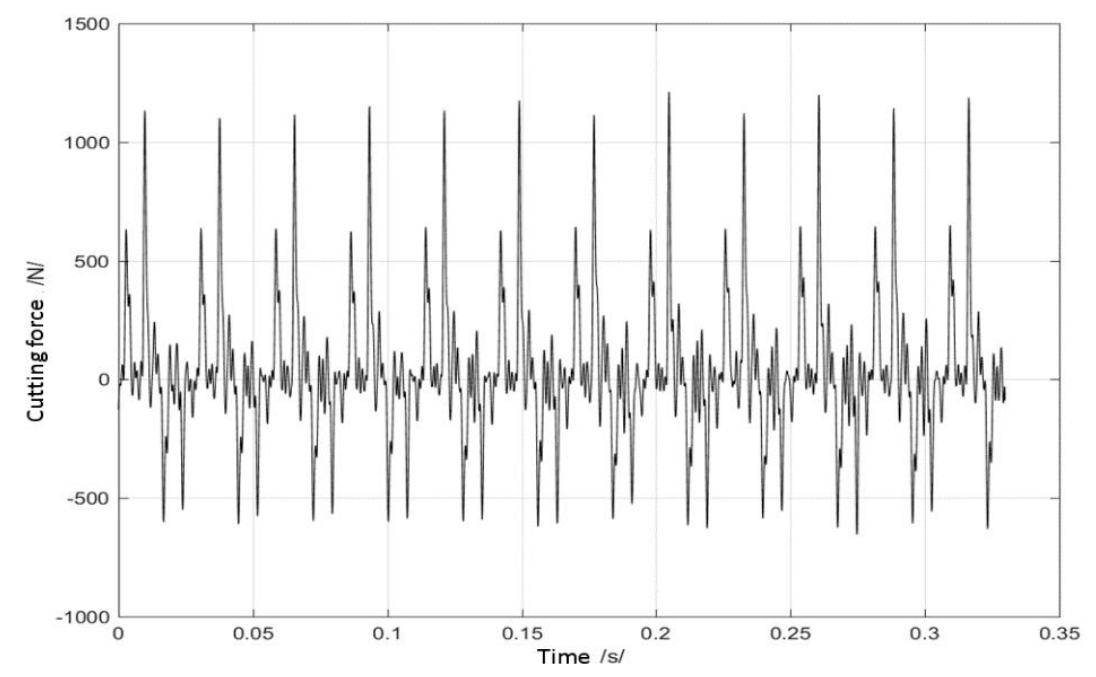

Fig. 6. Cutting force profile - micro-scale

In the finishing of sculptured surfaces, the macro-scale view is more important than the micro-scale one. The impact of the micro-scale profile on the quality of the finishing process arises from the inherent features of the milling process and is virtually independent of the strategy used for tool path generation. On the other hand, the macro-scale profile is substantially dictated by the strategy chosen and therefore becomes the key to the process.

\subsection{Evaluation of finished surface quality}

Suitable indicators for quality evaluation include surface roughness, macro-scale surface profile, and, understandably, findings from visual inspection.

The number of surface characteristics available today is very large. Practically, the most widely used ones include Ra and $\mathrm{Rz}$ values. Thanks to optical scanning devices, areal roughness is being used more frequently as well. Its information value is not to be overstated but the method is suitable for sculptured surfaces thanks to contactless measurement.

One appropriate indicator might be the arithmetic mean deviation of the profile calculated according to:

$$
R_{a}=\frac{1}{n} \times \int_{1}^{n}\left|Z_{(x)}\right| d x[\mu m][11]
$$

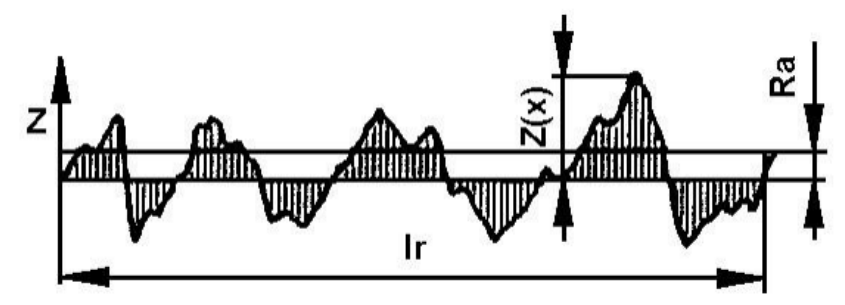

Fig. 7. Illustration of the arithmetic mean deviation of the profile Ra [11] 
It is advisable to verify the Ra value by theoretical calculation based on the specified feed rate for the milling process:

$$
R_{a}=\frac{f_{z}^{2}}{n^{2} \times z^{2} \times 31,2 \times r_{n}}[\mu m] \quad[12]
$$

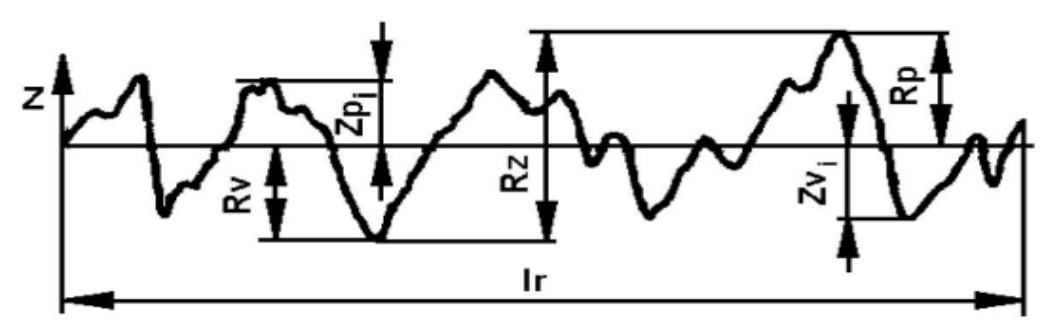

Fig. 8. Other roughness parameters, including Rz [11]

One can also use the arithmetic mean spacing between five peaks and valleys calculated as:

$$
R_{Z}=\frac{\sum_{i=1}^{5}\left|y_{p m i}\right|+\sum_{i=1}^{5}\left|y_{r m i}\right|}{5}[\mu m][11]
$$

Dimensional analysis and evaluation of individual dimensions of a sculptured surface tend to be difficult. A convenient approach uses measurement by a scanning device and an evaluation of the deviations from the 3D model.

It would be useful to compare the values of cutting forces, evaluate their profiles throughout the measurement run, and their envelopes. In addition, it is possible to evaluate the total cutting force using the following formula:

$$
F=\sqrt{{F_{x}}^{2}+{F_{y}}^{2}+F_{z}^{2}}[N]
$$

In order to compare the forces that arise in individual strategies, one can calculate the statistical mean value according to:

$$
\bar{F}=\frac{1}{n} \times \sum_{i=1}^{n} F_{i}[N]
$$

Correlation of qualitative parameters and dimensional values with the values and profiles of cutting force in individual strategies will reveal the dependences, on the basis of which optimized finishing strategies can be developed.

\subsection{Summary}

From the viewpoint of finishing operations which impart the final quality and dimensional accuracy to the machined surface, the macro-scale profile of cutting force is the key factor. It is because it is affected by the machining strategy which is the topic of the next section. In order to solve this problem, one needs to gain a comprehensive understanding of the cutting process at the finishing stage, and of the impact of individual force components on the quality and dimensional accuracy of the machined surface, and find correlations between these factors.

\section{Tool path strategy}

Fundamental differences in the tool behavior can be seen between climb milling and conventional milling. The distinction between these two techniques is well known. When dealing exclusively with finishing strategies, the choice of the technique does not have as strong effect as in other stages. The reason is that the load on the tool is relatively low and does not reach critical levels. Therefore, both techniques can be used without any substantial qualitative differences, and time savings can be achieved by eliminating non-cutting traversing movement.

Much greater impact is related to the feed and pick feed directions with respect to the inclination of the surface. All variants are illustrated in Fig. 10.

The first option involves horizontal feed and vertical downward pick feed. The above strategy is referred to as linear machining and is optimal for surfaces with steeper inclination angles, approximately $75^{\circ}$, as suggested in [3]. Here, this strategy leads to the lowest cutting force and to the most favorable variation in the cutting force. This strategy involves 
downward tool movement and typically leads to abrasive wear on the tool flank. The flank wear tends to be uniform, as shown in Fig. 9 a).
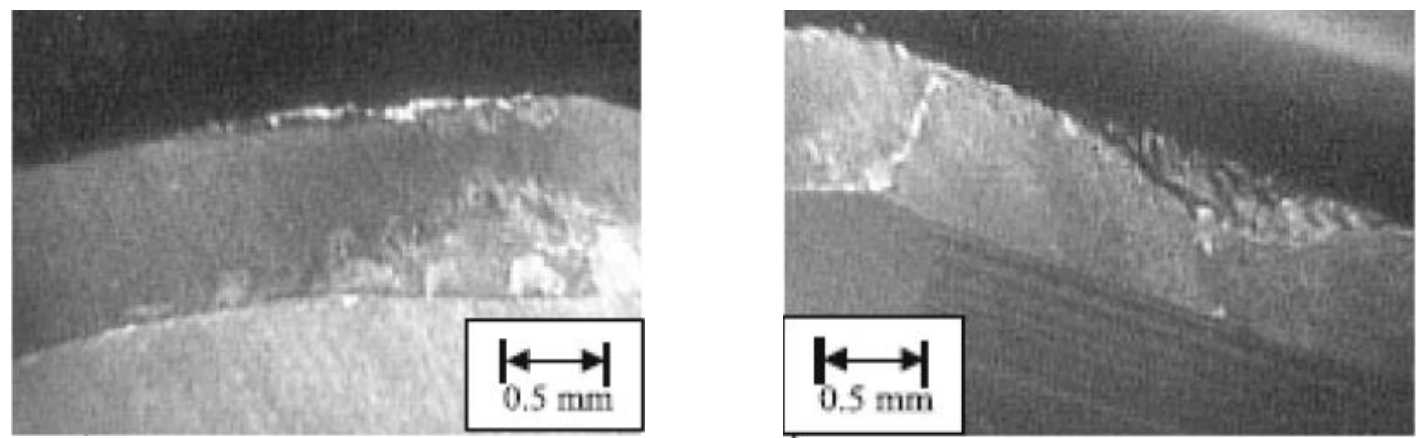

Fig. 9. Tool wear upon a horizontal feed process: a) downward, b) upward [2]

If the strategy involved the same horizontal feed but upward pick feed direction, these forces would increase. The variation would be from 60 to $200 \%$, predominantly in the $\mathrm{F}_{\mathrm{y}}$ component. This force acts in the normal direction with respect to the workpiece surface and has a major impact on the resulting quality and dimensional and geometric accuracy. The mechanical load on the tool is higher as well. The force profile is similar to the first case. Cutting edge chipping may occur, as illustrated in Fig. 9 b). [6]

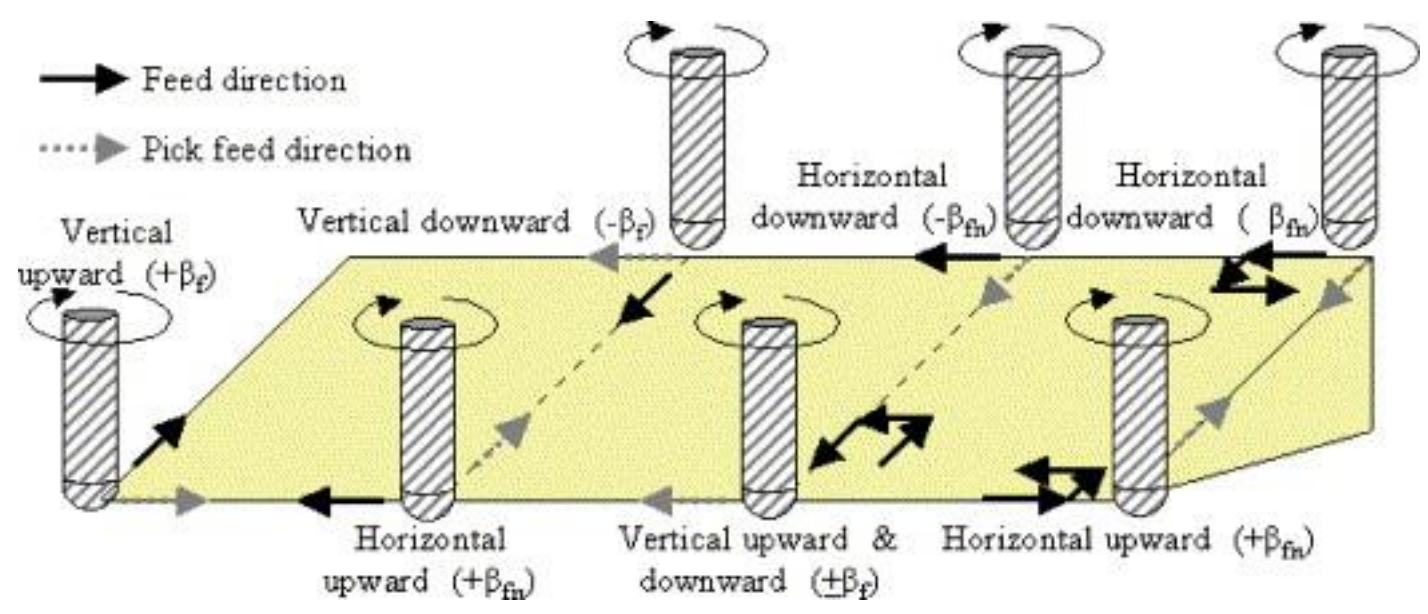

Fig. 10. Tool path strategy [7]

Another option of those listed in Fig. 10 involves vertical feed direction, and starting the cutting process at the top. The pick feed direction is horizontal. In this strategy, the material is being pushed in front the tool. As a result, the tool may deflect toward the workpiece, predominantly due to the Fy component of the cutting force. The variation in the cutting force might range from 30 to $300 \%$. This strategy is appropriate for surfaces with mild inclination, less than $25^{\circ}$ $[3,7]$.
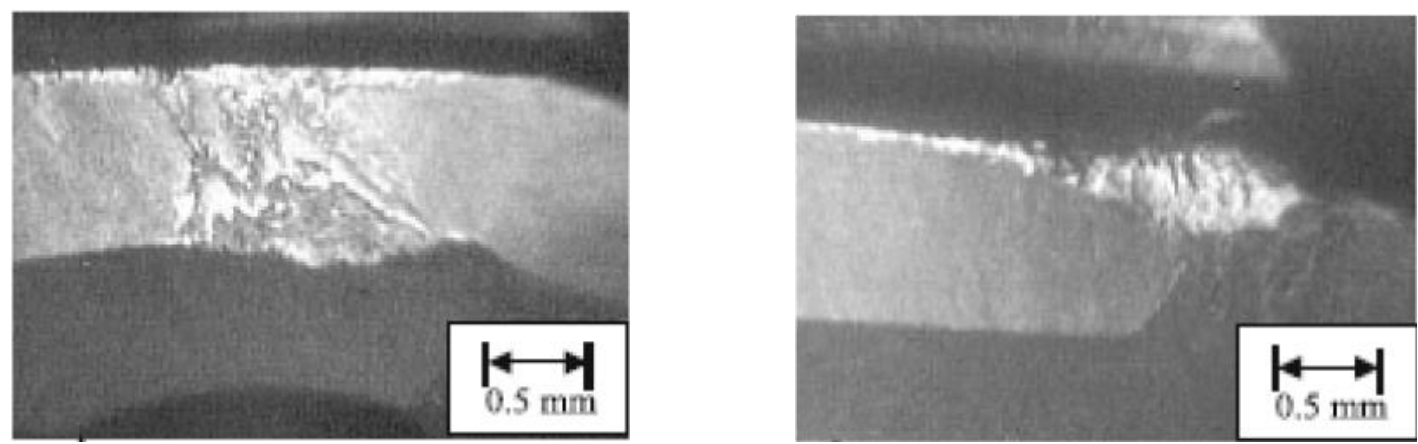

Fig. 11. Tool wear upon vertical feed: a) downward, b) upward [2]

No major change will be registered when machining starts at the bottom and ends at the top of planar surfaces with mild inclination angles. 
Near-planar surfaces with inclination angles under $15^{\circ}$ are better produced using form-duplicating strategies, according to [13], but the wear is more severe due to lower cutting speed. On surfaces with inclination angles around $45^{\circ}$ none of the strategies leads to markedly better results.

These conclusions are based on the literature sources cited, as well as on experiments carried out at University of West Bohemia [6], [8].

\subsection{Effect of strategy on dimensional accuracy}

As mentioned above, an important aspect of the result of machining is the quality of the machined surface. However, an equally important factor is its dimensional accuracy. Figure 12 a) shows an example of two machining strategies on a shape surface: linear machining and form-duplicating machining.
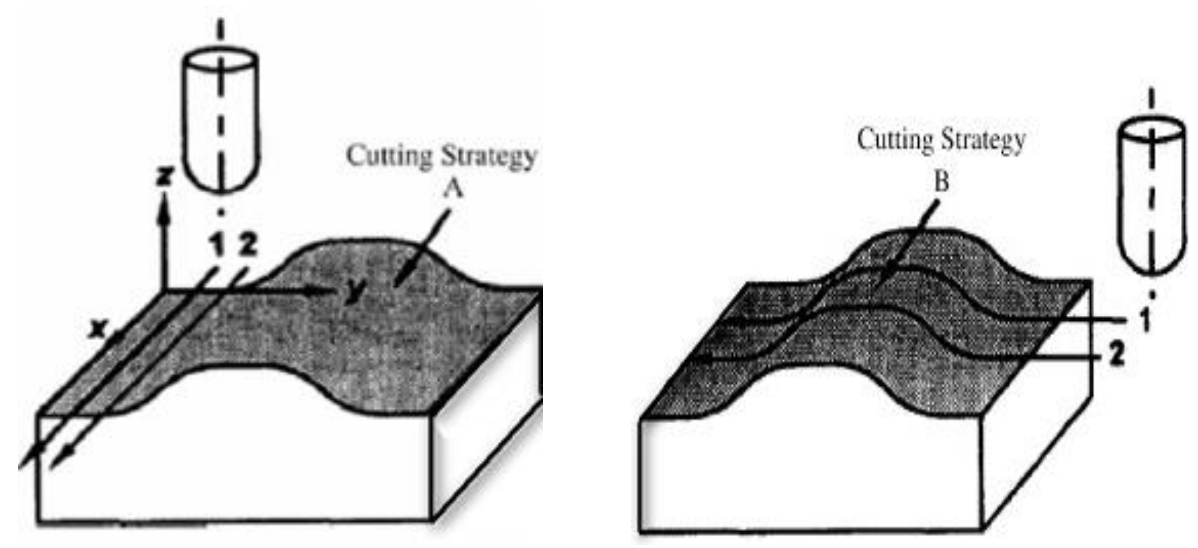

Fig. 12. Schematic representation of tool paths for a) linear machining strategy, b) form-duplicating machining strategy

Strategy A is a linear machining strategy with an upward vertical pick feed direction. We will not explore the suitability of this strategy for a particular shape surface. Instead, we will focus on the dimensional accuracy of the finished surface shown in Fig. 13. We will find that it is not uniform. The largest deviations from the nominal values are produced as the tool descends. While the tool is ascending, dimensional errors arise as well but their magnitude is smaller. The main reason is the variation in the cutting force in various parts of the shape. In particular, this applies to the component that is normal to the surface.

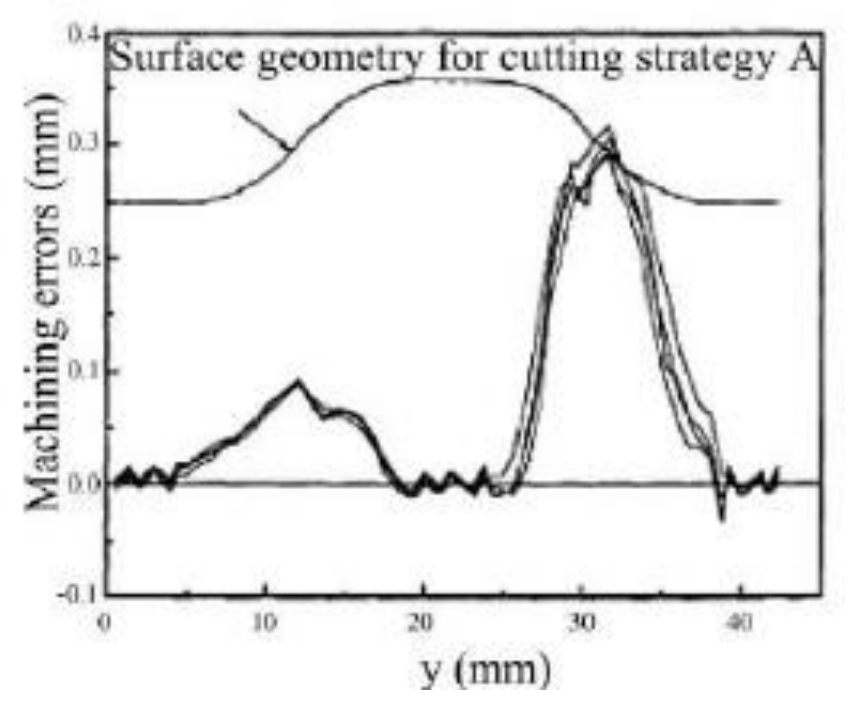

Fig. 13. Dimensional accuracy upon machining with strategy A [1]

By contrast, strategy B shown in Fig. 12 b) traces the shape of the workpiece in the horizontal direction and the pick feed is perpendicular to the feed direction. The texture of the finished surface is completely different from that produced by strategy A. As the tool descends, incomplete cutting occurs. The reason is, again, the normal component of the cutting force. However, the amount of incomplete cut is less because the tool pushes the work in front. Conversely, as the tool ascends, it overcuts because it is being pulled into the work. The results are illustrated in Fig. 14. 


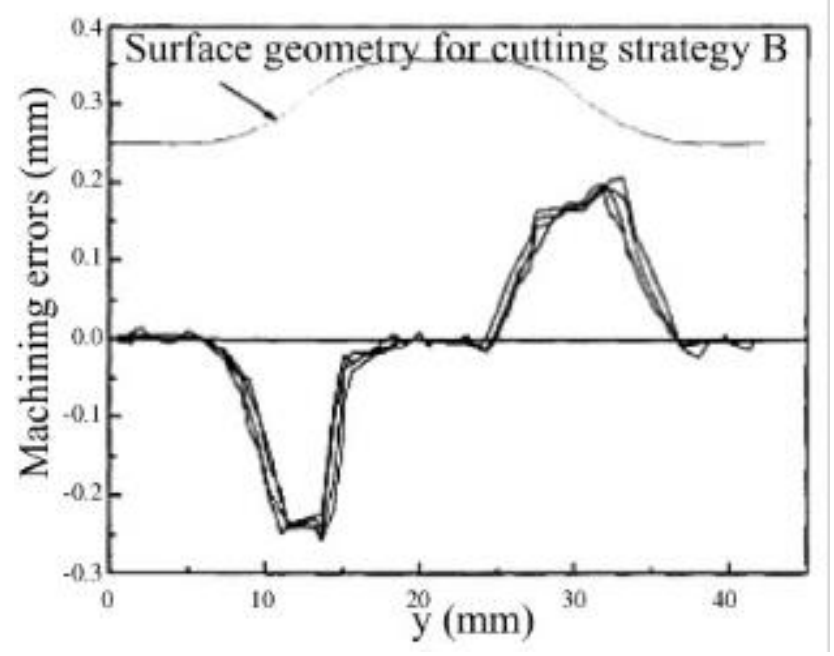

Fig. 14. Dimensional accuracy upon machining with strategy B [1]

These data suggest that the finishing strategy has a major impact on the accuracy of the finished surface. The same can be expected to hold for the quality of the finished surface, although this is not certain as no data on the surface quality are available in this respect.

\subsection{Summary}

The above-named strategies represent the fundamental available approaches to calculating tool paths for general shape surfaces. In many regions of such surfaces which are, in one way or another, approaching some limit, these strategies begin to fail. In these regions, the pre-set parameters undergo changes - which either impairs the quality of the shape surface or increases the machining time prohibitively.

Besides the machine, the tool, and the properties of the work, the shape itself also dictates the quality of the finished surface. The reason is the changes in the cutting force or more precisely in some component of the cutting force. Such changes affect the other parameters, such as cutting speed, chip volume, stock allowance for finishing, and others. In order to be able to propose a finishing strategy which, at least in part, improves the state of the art, these aspects must be investigated in greater depth. This will be the objective of the next part of the research

\section{Conclusion}

This study explores modern effective finishing of sculptured surfaces, i.e. one part of the field, which concerns the effect of the tool path strategy on the quality and geometric and dimensional accuracy of the finished surface. Despite today's advanced computing hardware and CAM software tools, finishing operations remain a challenge.

Algorithms that improve the effectiveness of tool paths in finishing are available. Unfortunately, their implementation in automation and CAM systems is so complicated that even today none of the above-named algorithms is part of any commercial manufacturing support software. Consequently, finishing paths have inadequate dimensions, e.g. too small stepover, or combine multiple operations, which is very time-consuming and inefficient because of the overlap of paths.

All these drawbacks have mostly negative effects on geometric accuracy of the finished surface, and lead to nonuniform quality. Together with finishing time, the quality and geometric accuracy are the fundamental indicators of effectiveness of any particular process. The reason is that these indicators show whether the condition of the surface is adequate or whether reworking is necessary, which involves additional machining costs.

In order to be able to prove the effect of cutting parameters in a particular strategy, quality and dimensional accuracy must be linked to a parameter which reflects virtually all changes that occur during machining. This parameter is the cutting force. It varies with almost all changes in the fundamental parameters. Cutting force, specifically its components, is a suitable parameter for evaluating finishing operations. One reason is that its amplitude gives a clear indication of changes in the process, and the other is that its overall profile can be used for tracking the effects of the strategy, finding correlations with the surface quality, and with the geometric accuracy of the finished surface.

Such conclusions can be drawn on the basis of the above-described facts. Further research will aim at finding correlations of the quality and geometric and dimensional errors of the machined surface with variation in the cutting force, and at improving the effectiveness of finishing sculptured surfaces, and thus developing the entire discipline of machining. 


\section{Acknowledgments}

This paper includes results created within the project SGS-2016-005.

\section{References}

[1] E.M. Lim, H.Y. Feng, C.H. Menq, Z.H. Lin The prediction of dimensional error for sculptured surface productions using the ball end milling process. Part 1. Chip geometry analysis and cutting force prediction Int. J. Mach. Tools Manufact, 35 (8) (1995), pp. 1149-1169

[2] Toh, C. K.: A study of efects of cutter path strategies and orientations in milling, Journal of materials procesing technology 113(2004) 346-356

[3] Poulachon, Gérard, Patric GHIDOSSI, José Outeiro and David Prat. Procedes et moyens de fabrication: Support de cours- TPS. Cluny, 2013

[4] Czerech, Lukasz. Selection of Optimal Machining Strategy in the Manufacture of Elements Bounded by Curvilinear Surfaces. acta mechanica et automatica, 2013, 7.1: 5-10. http://www.degruyter.com/view/j/ama.2013.7.issue-1/ama2013-0001/ama-2013-0001.xml

[5] Sova, František. Technologie obrábění a montáže. $2^{\text {nd }}$ edition. Plzeň: University of West Bohemia, Faculty of Mechanical Engineering, 1998, 273 pages. ISBN 80-708-2449-2

[6] Řehoř, Jan. Literature search for the project Studium vysokorychlostního obrábění (HSC) ocelí vysoké pevnosti a tvrdosti, Plzeň: University of West Bohemia, Faculty of Mechanical Engineering, 2001

[7] Surface topography analysis in high speed finish milling inclined hardened steel [online]. School of Engineering (Mechanical), University of Birmingham, 2003 [Accessed 2016-01-04]. http://www.sciencedirect.com/science/article/pii/S0022460X03012598

[8] Hnatik, Jan, Lubos Kroft and Jan Kutlwaser. Constant chip volume machining. Elsevier Ltd. [online]. 2015, 7 [Accessed 2016-08-24]

[9] CAD.cz [online]. [Accessed 2015-09-09]. http://www.cad.cz/pdmplm/7-2007/1377-petiose-obrabeni-v-praxi.html

[10] CAD-FEM.CZ, A Blog Of The Company Pemavako S.R.O. [online]. [Accessed. 2015-09-09]. http://cadfem.cz/component/content

[11] GAJDOŠÍK, D. Měření drsnosti povrchů se zaměřením na měřící techniku Mytutoyo SJ 210. České Budějovice, 2013. Bachelor thesis. University of South Bohemia in České Budějovice. Supervisor PaedDr. Bedřich Veselý, Ph.D.

[12] A.B. Abdullah, L.Y. Chia and Z. Samad, 2008. The Effect of Feed Rate and Cutting Speed to Surface Roughness. Asian Journal of Scientific Research, 1: 12-21

[13] Vopát Tomas, Peterka Jozef, Kováč Mario, Buranský Ivan, The Wear Measurement Process of Ball Nose end Mill in the Copy Milling Operations, Procedia Engineering, Volume 69, 2014, Pages 1038-1047, 24th DAAAM International Symposium on Intelligent Manufacturing and Automation, 2013

[14] Tunç, Lütfi Taner; Ozkirimli, Omer Mehmet; Budak, Erhan. Machining strategy development and parameter selection in 5axis milling based on process simulations. The International Journal of Advanced Manufacturing Technology, 2015, 118. http://link.springer.com/article/10.1007\%2Fs0017001580016

[15] Nittler, Kevin M.; Farouki, Rida T. A realtime surface interpolator methodology for precision CNC machining of swept surfaces. The International Journal of Advanced Manufacturing Technology, 2016, 83.14: 561574. http://link.springer.com/article/10.1007\%2Fs001700157552x

[16] Moodleah, S.; Makhanov, Stanislav S. 5axis machining using a curvilinear tool path aligned with the direction of the maximum removal rate. The International Journal of Advanced Manufacturing Technology, 2015, 80.14: 6590. http://link.springer.com/article/10.1007\%2Fs0017001569589

[17] Imania, B.M., M.H. Sadeghib A M.A. Elbestawia. An improved process simulation system for ball-end milling of sculptured surfaces. International Journal of Machine Tools and Manufacture [online]. 1998, (38) [Accessed 201609-06]. http://www.sciencedirect.com/science/article/pii/S0890695597000746 